\title{
Internal Control Implementation in Mitigating Significant Fraud Risk to Control Sales
}

\author{
Elizabeth Tiur Manurung \\ Accounting department of Economics Faculty \\ Parahyangan Catholic University \\ Bandung, Indonesia \\ eliz@unpar.ac.id
}

\author{
Greata Octo \\ Accounting department of Economics Faculty \\ Parahyangan Catholic University \\ Bandung, Indonesia
}

\begin{abstract}
The reason behind this study is the fact that company faces more and more competition in this ASEAN Economic Community Era. The company have to achieve and maintain their efficiency to win the competition. Then, the purpose of this research is to identify whether there is potential fraud risk in PT. PCPT, and how to mitigate significant fraud risk to make the company still in their efficiency. The method used in this research is analytical descriptive, whereas this method show a measurement and description about the reality of object which is being research. Data collection technique uses inquiry, questionnaire, and observation. Analysis will be based on comparison of these two to find out how internal control can solve potential significant fraud risk. The paper describe there are three potential risk fraud, namely (1) cash bribery by Salesman in collecting accounts receivable; (2) material bribery by plant manager; and (3) sales managers will increase sales volume by treat the sales of next period became this period. All potential fraud can be solved by internal control. Then, all activities in sales cycle become more effectiveness and efficient, and in other words sales cycle well controlled; and can be used as sales accountability to the users.
\end{abstract}

Keywords-Fraud risk; Fraud risk registe; fraud risk assessment, internal control; misappropriation of assets; fraudulent of financial statement

\section{INTRODUCTION}

As we all know, global market has significant impact to our market competitiveness, this will result in sharper market competition. Indonesian companies have to search a new way to maintain their effectiveness and efficiency on their operation, to maintain their revenues. Fraud as one of the variable that can impact their efficiency, is taking many cost to company and will reduce profit.

Company will try to eliminate fraud as possible as they can, like implementing effective Internal control as they believe will create double checking in treating all transaction that cured. Ananda (2014) research came up to result that internal control can mitigate fraud of making double cash receipt, the absence of access password and the mistake of sales period recording. This term means if fraud can be well manageable then efficient operation can be achieved, furthermore company can reach the maximum profit. And since, company could maintain their profit consistently each period and achieve more and more profit, then their operation will be maintained continuously. And finally, reliable company's accountability to all stake holders will be achieved.

Based on explanation above, this research will focus on Internal control of Sales cycle in PT. PCPT, which Research questions are: (1) How is the result of fraud risk assessment implementation in Sales and collecting cycle; (2) How is the role of internal control of Sales cycle in mitigating/ reducing fraud of Sales division.

\section{THEORETICAL REVIEW}

\section{A. Internal Control}

In this study, the explanation of internal control is as Wilkinson said, that Internal control is consist of policies and procedures that are implemented by management and their staff so that company could achieve their goals and targets (Romney et. Al: 2009). And usually, the goal of the firm is to maximize shareholders' value (Brigham: 2016) and internal control could reach the goals trough (1) safeguard the company assets; (2) create the reliability of report and information; (3) achieve an efficient operation; (4) and as a trigger to the company to do their operation which complies to regulation.

\section{B. Fraud Audit}

Fraud, according to Arens, et al. (2013), is a term used to describe various types of action taken to take other people's rights or ownerships. Fraud can be classified into three general categories, namely fraudulent statements, asset misappropriations and corruption. (Arens, et al., 2013). Basically fraud can be occur caused by 3 conditions: (1) Pressure. Arens, et. Al (2013: 355); (2) opportunities, and (3) is Rationalization. As Ananda research (2015) found that theft of cash by cashier is because of pressure and opportunities.

\section{METHODS}

\section{A. Research Method}

This research uses Analytical descriptive method. This method revealed the information about Company's sales and collection Procedures, Flow of document of sales and collection cycle, Credit division, and review result of the internal control of sales procedures. In this case, we especially analyze how Internal control can take part in decreasing significant Sales Fraud. 


\section{B. Data collection}

This research used primary data such as questionnaire and observation result, and secondary data like company's Financial Statement, and literature study. The questionnaire is developed based on measures use in previous related studies to gain information on the potential fraud in the company. All data will be obtained by collecting, observe and fulfill the questionnaire, and will be analyzed with logical thinking to generate conclusion and which uses analysis approach

\section{DISCUSSION}

The first step is identify fraud risk factors. This study used two questionnaire to identify fraud risk factor, that are fraud risk factor which is related to fraudulent financial reporting and misappropriation of assets. The analysis for each finding of fraud risk factor will be based on tree elements of fraud, that are pressure, opportunity and, Rationalization.

Fraud risk register is used to identify fraud risk significant which explained that every fraud risk factor can happened, and doing assessment based on the opportunities of likelihood to occur (L) and impact (I). the grade that indicated how the probability risk will occurred for both components are high, medium, and low. The result from likelihood and impact will be combined in combined risk (CR), which is interpretation grading as high, medium, or low. Significant risk is risk which is had both impact and likelihood high (IFAC, 2010b, h.121).

\section{A. Potential Fraud Related to Fraudulent Financial Reporting}

(1) Sales managers will increase sales volume by treat the sales of next period became this period. Our assessment and analysis of this fraud is a medium risk, due to for audited financial statements by an external auditor. But if the act of fraud does happen, then there will be material misstatement that impact rated high. Then with the medium likelihood and high impact, combined risk or composite risk are obtained so that the risk is not considered significant. We concluded that This fraud affected by pressure, opportunities and rationalization. This finding similar with previous research by Hermina (2014) that is early recognition of sales; and also by Manurung \& Hardanu (2016) is manipulating Sales.

\section{B. Fraud Risk related to Misappropriation of Assets}

Based on the information obtained and analyzed, here's the discussion of identified risks related to assets misuse.

\section{(1)Cash bribery by Salesman in collecting accounts receivable}

The risk of this theft of cash receive (cash larceny), Assertion that involved in cash larceny and Lapping are completeness and accuracy of financial statements. The possibility of fraud stands in medium range, various impact cause from misappropriation of assets stand in high range so that combined risk medium that indicate the risk are not significant. This fraud affect by pressure, opportunities and rationalization. This finding is similar with previous research of Hermina (2014) and Manurung \& Hardanu (2016).

\section{(2) Un-authorized discount by salesman}

Salesman can give certain discount rate to customers without authorized by Sales manager, and customers willing to pay salesman for got a discount. The combined or composite risk valued is not significant.

Internal control mitigation is to set a procedure of authorization by sales manager for each discount given to customer. We concluded that This fraud affect by pressure, opportunities and rationalization.

\section{(3) Material bribery by plant manager}

Material theft by plant manager occurs when there are a lot of material left at plant site. Plant manager or employees can sale this residual material to other parties. Therefore, the likelihood is valued high and also the impact is valued high, resulting in high combined risk and significant.

Activities control to detect this fraud is comparing among ending balance material report and material requisition document. We concluded that This fraud affected by opportunities and rationalization.

After gaining an understanding of company internal control, the next step is assess the internal control. The description bellow, is about relationship between Implementing satisfy internal control and fraud risk in sales cycle.

TABLE I. CONTROL DESIGN MATRIX

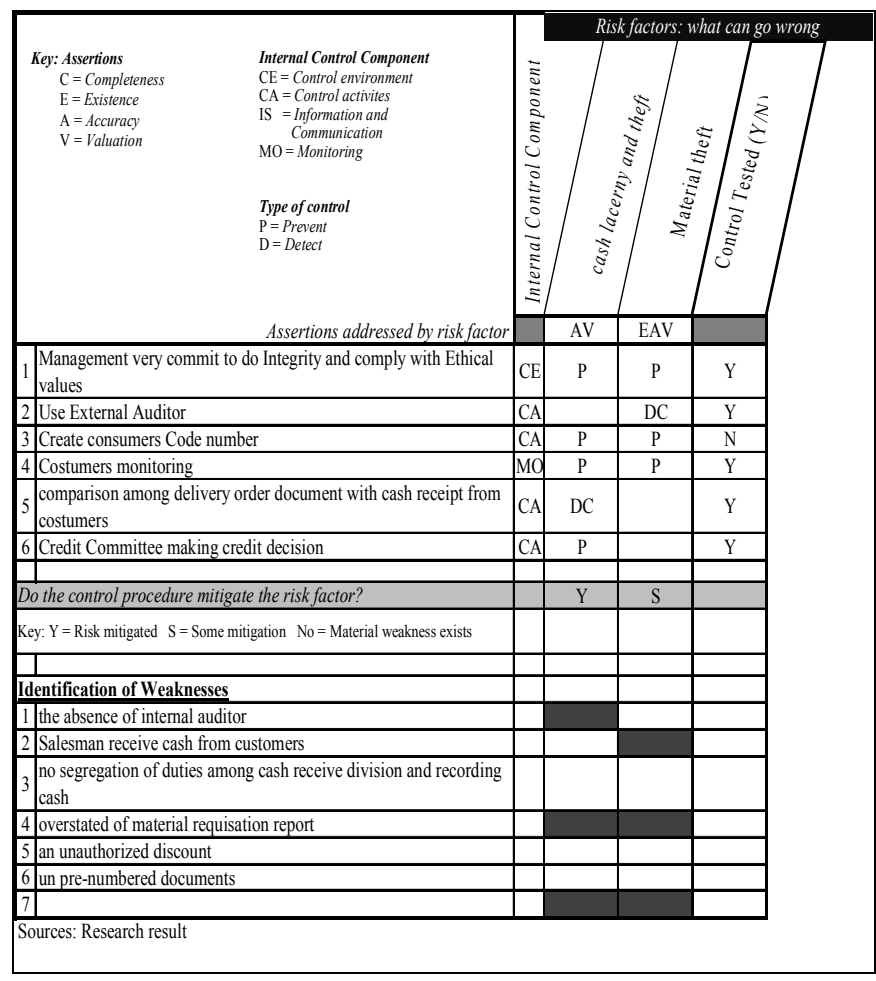


From table 1, we show that internal control of cycle sales in TP. PCPT satisfy enough to detect potential fraud risk.

\section{c. Understanding The Internal Control.}

The result of Internal control questionnaire based on COSO Internal Control-Integrated Framework, shows bellow.

TABLE II. THE RESUlt OF THE INTERnAL CONTROL QuestionNAIRE

\begin{tabular}{|l|l|l|l|l|}
\hline & $\begin{array}{l}\text { Component of Internal } \\
\text { Control }\end{array}$ & Yes & No & TR \\
\hline 1 & Integrity \& Ethical Value & 5 & 1 & 0 \\
\hline 2 & Commitment to competence & 2 & 2 & \\
\hline 3 & $\begin{array}{l}\text { Board of Director \& Audit } \\
\text { Committee participation }\end{array}$ & 7 & 1 & 0 \\
\hline 4 & $\begin{array}{l}\text { Philosophy \& operating style } \\
\text { of Management }\end{array}$ & 1 & 1 & 0 \\
\hline 5 & Organizational structure in & 1 & 1 & 0 \\
\hline 6 & $\begin{array}{l}\text { Policies \& Practices in } \\
\text { Human Resources }\end{array}$ & 2 & 0 \\
\hline 7 & Risk Assessment & 14 & 3 & 0 \\
\hline 8 & Control Activities & 5 & 1 & 0 \\
\hline 9 & $\begin{array}{l}\text { Communication } \\
\text { Information }\end{array}$ & 2 & 1 & 0 \\
\hline 10 & Supervision & & & \\
\hline
\end{tabular}

Resources: Research Result

Based on questionnaire which has been used, the company already has a satisfy internal control relating to manage risk in Sales division, especially for risk assessment, activities control, participation of The Board of Directors and Audit committee, also in Human Resources division.

\section{CONCLUSION}

Overall, the result show that each type of fraud is associated with fraudulent financial reporting and misappropriation of assets. As expected, fraud revealed cause of three factors, such as (1) pressure, (2) opportunities, and (3) rationalism. It can be concluded, there are several potential fraud such as, (1) Cash bribery by Salesman; (2) material bribery by plant manager; (3) un-authorized discount; and (4) sales managers will increase sales volume by treat the sales of next period became this period, that will impact on fraudulent of financial statements. All potential fraud can be solved by internal control of sales cycle, then, all activities in sales cycle become more effectiveness and efficient, and can be used as sales accountability to the users.

Several recommendations could be given to increase internal control, are (1) Company should be used prenumbered sales document, (2) Company should segregate duty between cash receive division and recording cash division, (3) Cash from customers should be receipt through Bank transfer, (4) each discount transaction should be authorized, and (5) material report should be compareds with material requisition report.

\section{ACKNOWLEDGEMENT}

Thank you to Hardanu, Hermina, and Ananda for sharing the research result.

\section{REFERENCES}

[1] Arens, AA., RJ Elder., MS Beasley, and CE Hogan. (2017). Auditing and Assurance Services: An Integrated Approach. 16th edition - Global edition. New York: Pearson.

[2] Dorf, RC. (1983) Sistem Pengaturan. Edisi 3, Erlangga: Jakarta.

[3] Goldmann, Peter D. (2010). Financial Services Anti-Fraud Risk and Control Workbook. Canada: John Wiley \& Sons, Inc.

[4] International Federation of Accountants. (2010a). Guide to Using International Standards on Auditing in the Audits of Small- and MediumSized Entities: Volume 1. New York: Small and Medium Practices Committee International Federation of Accountants.

[5] International Federation of Accountants. (2010b). Guide to Using International Standards on Auditing in the Audits of Small- and MediumSized Entities: Volume 2. New York: Small and Medium Practices Committee International Federation of Accountants.

[6] Manurung, Elizabeth T. 2016. Roadmap to Eliminate Corruption Through Development of Integrated Human. Asia Pasific Fraud Journal. Volume 1, No. 1st Edition (January - June 2016). Pp.129-136.

[7] The Institute of Internal Auditor. (2009). Internal Auditing and Fraud. http://www.theiia.org/chapters/pubdocs/56/Terry-BurkeIIA_fraud_risk_assessments.pdf. 